\title{
Geographic distribution of West Nile virus reported in humans and corvids in southern Ontario, 2006
}

\author{
Ashleigh B. Sullivan and Olaf Berke \\ This manuscript was prepared under the supervision of Professor Olaf Berke, \\ Department of Population Medicine, Ontario Veterinary College.
}

\begin{abstract}
This study analyzes the spatial risk distribution of West Nile virus (WNv) in humans and birds across southern Ontario for 2006. The relationship between bird and human risk is also investigated. Surveillance data was obtained for the number of human WNv cases and the fraction of dead birds testing positive in each public health unit. The presence of disease clustering in humans and birds was investigated using a spatial scan test. Choropleth risk maps of regional empirical Bayesian smoothed estimates were created to investigate the spatial distribution of WNv in humans and birds. Isopleth risk maps were created through kriging of smoothed estimates, and were used to identify high-risk areas as well as investigate the relationship between human and bird risk. One disease cluster was found in both humans and birds. The human disease cluster was not significant when the bird data was used as a covariate in the analysis. The choropleth and isopleth maps identified the southern portion of southern Ontario to be the highest risk area for both humans and birds. This study indicates that bird outbreaks are a potential indicator for an increase in human risk. As well, WNv risk is greatest in the southern portion of southern Ontario and is geographically spreading in comparison to previous years.
\end{abstract}

$\mathrm{W}$ est Nile virus (WNv) was first isolated in 1937 from a patient in the West Nile district of Uganda. ${ }^{1}$ In 1999 , the virus was introduced into the United States and led to an outbreak in New York City, which resulted in seven human case fatalities. $^{2}$ In 2001 and 2002, the first Canadian bird and human cases were detected in Ontario, respectively. ${ }^{3}$

The United States Centre for Disease Control and Prevention (CDC) has estimated that $80 \%$ of humans infected with WNv will be asymptomatic and more than $19 \%$ will develop West Nile fever, which includes general flu like symptoms. ${ }^{4}$ The remaining one in 150 human cases will lead to severe West Nile disease which involves the nervous system and may include meningitis, encephalitis, paralysis, or death. ${ }^{4}$

The life cycle of WNv involves birds and mosquitoes. Birds act as the reservoir since once they are infected they amplify the virus allowing for further transmission. ${ }^{5}$ Mosquitoes act as a vector and feed on infected birds. During later blood meals, mosquitoes can transmit the virus either to other birds or a dead-end host. ${ }^{6}$ For WNv, dead-end hosts most often include humans and horses. ${ }^{7}$ Mosquitoes are also able to transmit the virus vertically; and infected females have been shown to hibernate over winter and still be infectious the following season. Though it is unknown how often these transmission processes occur in nature. ${ }^{8,9}$ The Culex species are thought to be the primary mosquito type involved in WNv transmission. ${ }^{10} \mathrm{WNv}$ has been identified in 255 bird species, however the primary species of importance for transmission remains unknown. ${ }^{11,12}$
In 2000, the Public Health Agency of Canada established a surveillance program to respond to the discovery of WNv in the United States. ${ }^{13}$ This surveillance program included monitoring the virus in humans, birds, mosquitoes and horses. In 2006, dead birds of the Corvidae family were tested to monitor the virus in birds. ${ }^{14}$ Corvids are used as an indicator of the virus distribution in birds since they have a high mortality rate from WNv infection. ${ }^{15}$ Many studies have demonstrated that bird outbreaks of $\mathrm{WNV}$ typically precede an increase in human cases. ${ }^{16,17,18}$ For southern Ontario specifically, Beroll et al. ${ }^{19}$ discovered a significant association between the spatial pattern of $\mathrm{WNv}$ risk in humans and birds.

The aim of this study was to investigate the spatial distribution of $\mathrm{WNv}$ in humans and birds for southern Ontario in 2006. A secondary aim of the study was to provide further inside into the potential of $\mathrm{WNv}$ dead bird surveillance as basis for an early warning system for public health.

\section{METHODS}

For southern Ontario in 2006, the number of birds tested for $\mathrm{WNv}$ as well as their disease status was obtained from the Canadian Cooperative Wildlife Health Centre (CCWHC). ${ }^{20}$ The number of detected human cases in each public health unit was collected from the Ontario Ministry of Health and Long Term Care (OMHLTC). ${ }^{21}$ Population estimates for 
public health units in 2005 as well as the corresponding boundary map was acquired from Statistics Canada. ${ }^{22,23}$

Dead bird surveillance in Ontario has relied on voluntary reporting by the public. ${ }^{14}$ Reported dead birds are collected and sent to the CCWHC where oral swabs were taken and tested for $\mathrm{WNv}$ antigen. ${ }^{24}$ Human testing on the other hand relies on detecting antibodies of Wnv performed at the OMHLTC Central Public Health Laboratory. ${ }^{24}$ Because WNv is a reportable disease in Canada, human cases must be reported to local and provincial health authorities. ${ }^{25}$

Raw estimates of human incidence and bird mortality fractions (also known as bird proportional mortality fractions) were geo-located in the centroids of each public health unit. The estimates were used to identify clusters of disease in humans and birds separately using a spatial scan statistic. ${ }^{26}$ Human cases were rare and assumed to follow a Poisson distribution, and the more common bird cases a Binomial distribution. The attained level of significance ( $p-$ value) was estimated by the Monte Carlo method using 999 replications. ${ }^{27}$ A spatial scan test of human incidence when bird mortality fraction was treated as a covariate was also done to assess if in 2006, bird mortality helped to explain human cases as has been previously found. ${ }^{19}$

Empirical Bayes estimation is used to adjust the raw estimates of human incidence and bird mortality fractions for their sample size. ${ }^{28}$ Choropleth maps of these adjusted incidence and mortality fractions were created to visualize the regional estimates.

Isopleth risk maps were created using ordinary kriging of the empirical Bayes estimates. ${ }^{29}$ Here, kriging was based on an exponential semivariogram fitted by maximum likelihood estimation.

The analyses involved the software: $\mathrm{R}^{30}, \operatorname{SaTScan}^{27}$ and ArcMap. $^{31}$

\section{RESULTS}

The raw bird mortality fractions ranged for the 29 health units in southern Ontario from $6.25 \%$ to $87.5 \%$. Raw human incidence ranged from 0 to 1.51 cases per 100,000 people. After the data were smoothed using empirical Bayes estimation, bird mortality ranged from $18 \%$ to $39 \%$ and human incidence ranged from 0.16 to 0.80 cases per 100,000 people. In total there were 31 human cases reported in southern Ontario for 2006. Choropleth maps displaying empirical Bayesian smoothed risk estimates for humans and birds can be seen in Figure 1a) and 1b) respectively. The disease in both humans and birds is concentrated in the southern area of southern Ontario.

One disease cluster was found in both the human and bird raw data. The p-values for the clusters were 0.01 and 0.003 respectively. The location of the clusters can be seen in Figure 1a) and 1b). There were 17 public health units included in the bird cluster and 10 in the human cluster. All 10 public health units that were part of the human cluster were also part of the bird cluster. When the bird data was used as a covariate for the scan test to detect clusters of human disease, none were detected.

For the human and bird data, maximum likelihood fit semivariogram models were of the exponential form without a nugget effect. Four public health units were treated as outliers and removed from the dataset when the maximum likelihood model was fit to the semivariogram for humans. These four units were all detected to be a part of the disease cluster in humans; however they displayed an unexpected low risk.

The human and bird isopleth risk maps resulting from kriging of the smoothed risk estimates can be seen in Figure 1c) and 1d) respectively. The Health Units with the highest smoothed human incidences were found to be: Brant County, Lambton, and Windsor-Essex County. It should be noted that the Windsor-Essex County health unit had the highest smoothed incidence at 0.80 cases per 100,000 people. Lambton and Brant County had the next highest smoothed incidence at 0.54 cases per 100,000 people. The health units with the highest bird mortality fractions were: MiddlesexLondon, Brant County, and the City of Toronto. The bird mortality fraction estimates in these three areas are all greater than $35 \%$.

\section{DisCUSSION}

The spatial scan statistic detected a human and bird disease cluster in the southern area of southern Ontario (see Figure 1a) and 1b) respectively). The cluster locations are consistent with findings from previous years, however the human cluster size is larger than had been detected in the past. ${ }^{19}$ The circular spatial scan statistic was used here for explorative purposes. This method is useful in determining the general location of disease clusters. It does not however detect all regions involved in clusters that are non-circular. For the exact location and extent of irregularly shaped clusters, other detection methods such as the spatial scan statistic by Tango and Takahashi ${ }^{32}$ may be more appropriate. This is likely why the Windsor-Essex Health Unit was not included in the bird disease cluster.

An outbreak of WNv in birds has been shown to precede an excess of human cases by two to five weeks. ${ }^{18}$ When the scan statistic was used to detect human clusters of disease with bird mortality fractions treated as a covariate, no clusters were found. This is consistent with findings from previous years and indicates that an outbreak location of $\mathrm{WNv}$ in birds has the potential to serve as a early warning system, i.e. it is possible to predict a high-risk area for humans. ${ }^{19}$ When an outbreak in birds is detected, local health authorities have about two weeks lead time to put preventative methods into place and limit the number of resulting human cases.

While the bird data is valuable for predicting an increase in human incidence, it does have limitations. In Ontario, bird surveillance has relied on the general public to report the locations of dead corvids. ${ }^{14}$ The effect of this bird sampling 

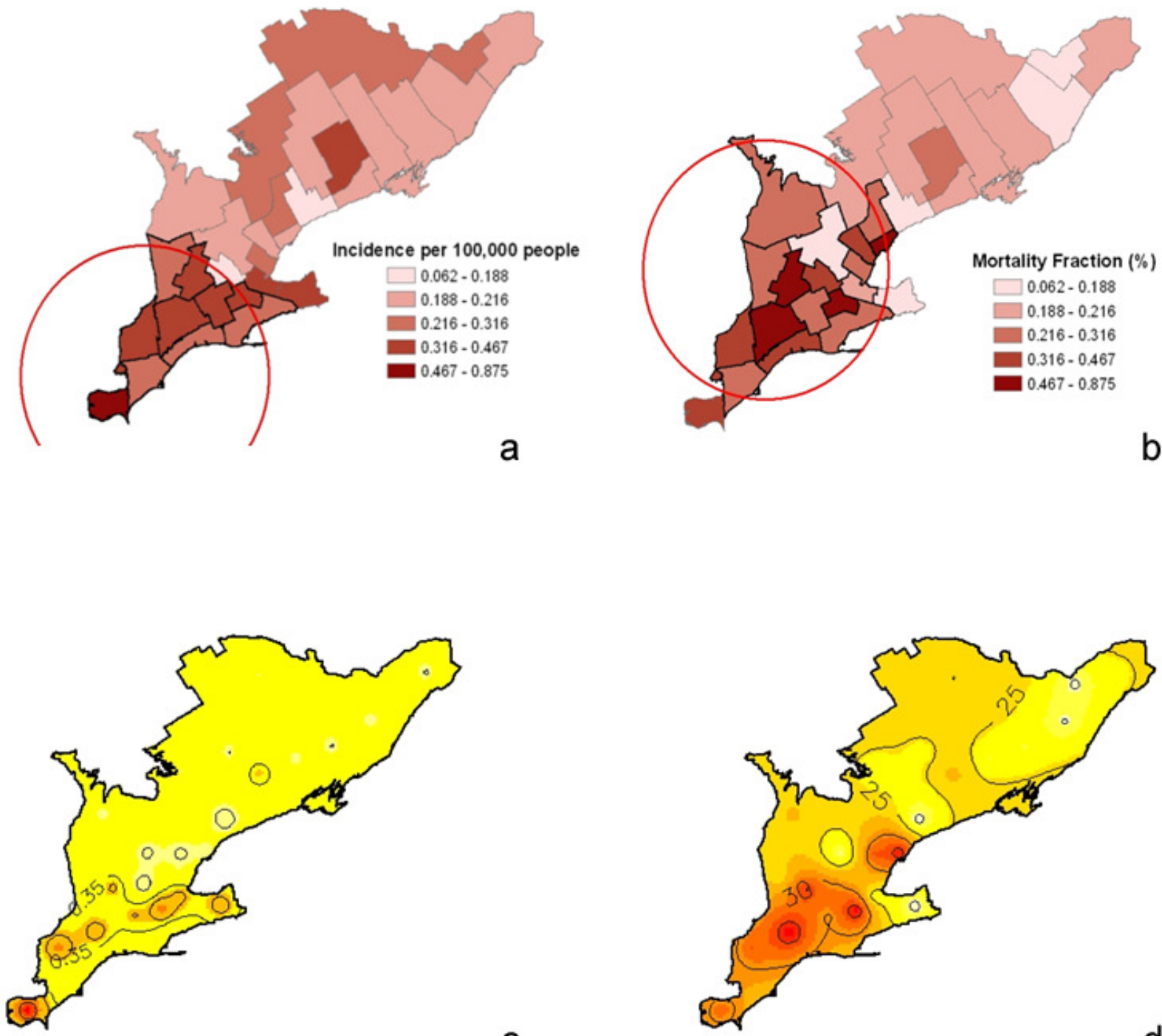

C

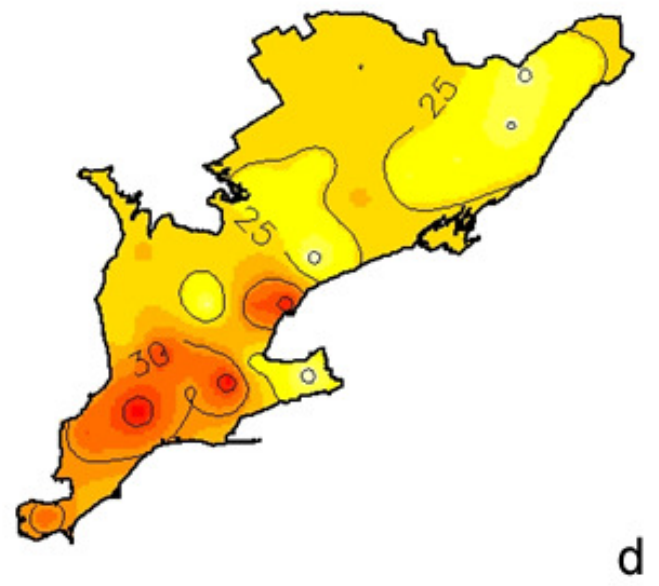

Figure 1 WNv risk estimates for the 29 public health units of southern Ontario in 2006. (a) Choropleth map of empirical Bayesian smoothed human incidence of $\mathrm{WNv}$ per 100,000 population overlaid with disease cluster location as detected by the scan test; (b) Choropleth map of empirical Bayesian smoothed bird mortality fractions overlaid with disease cluster location as detected by the scan test; (c) Isopleth map of smoothed human incidence estimates (per 100,000 population); (d) Isopleth map of smoothed bird mortality fraction estimates.

process being dependent on the public is not entirely understood. It is reasonable to assume that within a health unit, urban areas have been sampled more intensely than rural areas as a result of having a greater population density. This would lead to a mortality fraction that is more representative of urban areas if there is any difference. In addition, public health units have not been required to begin and end bird testing at the same time. Health units that have done the majority of their testing in the beginning of the season when WNv risk is lower would therefore have had a lower mortality fraction comparatively. In addition, localized disturbances in the multifactorial cause of death of corvids for reasons other than $\mathrm{WNv}$ infection may distort the mortality fraction in affected health units.

The overall Bayesian smoothed estimates of risk for humans and birds from 2002 to 2006 can be seen in Figure 2 and is based on a study by Beroll et al. ${ }^{19}$ as well as the findings from this study. Both human and bird $\mathrm{WNv}$ risk decreased from 2002 to 2004, and then increased in 2005. For 2006 however, the human incidence decreased drastically from 2.14 cases per 100,000 people to 0.32 , while the bird mortality fraction increased from $25.2 \%$ of birds testing positive to $27.8 \%$. Weather has been found to impact WNv transmission. ${ }^{33}$ The nearly seven-fold decrease in 


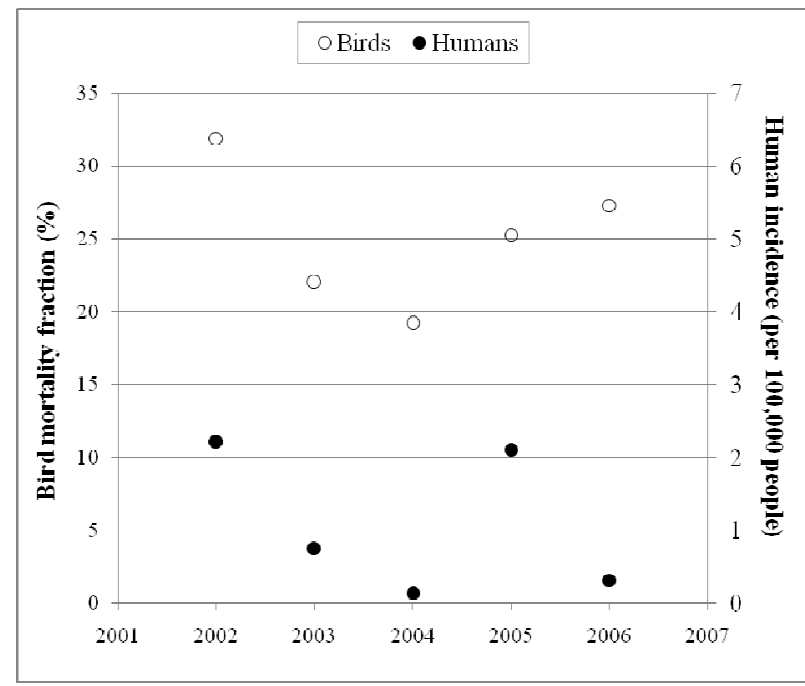

Figure 2 Trend in WNv risk for humans and birds in southern Ontario from 2002 to 2006.

human incidence may be a result of dry weather across southern Ontario in the late summer of 2006, which would have decreased the number of mosquitoes infecting humans. Another factor that may account for this decrease in human risk is an increase in public awareness of the virus and how to prevent infection.

Geographically, areas considered high risk in 2006 have expanded when compared to areas that were considered high risk in the past. In previous years, clusters of the disease in humans contained at most four health units and were focused in the Niagara, Toronto, or Windsor areas. ${ }^{19}$ In 2006 the human cluster of disease increased to include 10 public health units indicating a spread of the disease. In addition, high-risk areas were found outside of the Niagara, Toronto, and Windsor areas where increased risk had previously not been observed. The geographical spread is also demonstrated by the bird isopleth map, which displays high risk in the Middlesex-London health unit and the Brant County health unit, which have consistently been low risk areas in the past. ${ }^{19}$ While areas of comparatively high risk have expanded from 2005 to 2006 for both humans and birds, the overall risk for humans has decreased from 2005 while bird risk has increased.

The isopleth maps and spatial scan statistics indicate that both human and bird WNv risk is concentrated in the southern area of southern Ontario but is present all across southern Ontario. In addition, human risk continues to be spatially associated with bird risk and their cluster locations overlapped in 2006. Due to this spatial relationship, empirical Bayes smoothed bird mortality fraction continues to be an early warning indicator or increased human risk. This means that if bird outbreak locations are detected, prevention methods that are immediately put in place may control an outbreak in the human population.

\section{REFERENCES}

1. Smithburn KC, Hughes TP, Burke AW, Paul JH. A neurotropic virus isolated from the blood of a native of Uganda. Am J Trop Med Hyg 1940, 20:471-492.

2. Nash D, Mostashari F, Fine A, Miller J, O'Leary D, Murray K, Huang A, Rosenberg A, Greenberg A, Sherman M, Wong S, Layton M. The outbreak of West Nile virus infection in the New York City area in 1999. N Engl J Med 2001, 344:1807-14.

3. Public Health Agency of Canada. West Nile virus: History. Available online at http://www.phac-aspc.gc.ca/wnno/hist_e.html (Accessed October 1, 2007).

4. Centre for Disease Control and Prevention. Symptoms. Available online at http://www.cdc.gov/ncidod/ dvbid/westnile/qa/symptoms.htm (Accessed September 22, 2007).

5. Work TH, Hurlbut HS, Taylor RM. Indigenous wild birds of the Nile delta as potential West Nile virus circulating reservoirs. Am J Trop Med Hyg 1955, 4:872-88.

6. McLean RG, Ubico SR, Docherty DE, Hansen WR, Sileo L, McNamara TS. West Nile Virus Transmission and Ecology in Birds. Ann N Y Acad Sci 2001, 951:54-57.

7. Campbell GL, Marfin AA, Lanciotti RS, Gubler DJ. West Nile virus. Lancet Infect Dis 2002, 2:519-529.

8. Dohm, DJ, Sardelis, MR, and Turell, MJ. Experimental vertical transmission of West Nile Virus by Culex pipiens (Diptera: Culicidae). J Med Entomol 2002, 39:640-644.

9. Nasci RS, Savage HM, White DJ, Miller JR, Cropp BC, Godsey MS, Kerst AJ, Bennett P, Gottfried K, Lanciotti RS. West Nile Virus in Overwintering Culex Mosquitoes, New York

City, 2000. Emerg Infect Dis 2001, 7:4.

10. Turell MJ, Sardelis MR, Dohm DJ, O'Guinn ML. Potential North American vectors of West Nile virus. Ann N Y Acad Sci 2001; 951:317-24.

11. Hombach J, Barrett AD, Cardosa MJ, Deubel V, Guzman M, Kurane I, Roehrig JT, Sabchareon A, et. al. Meeting report: Review on flavivirus vaccine development Proceedings of a meeting jointly organised by the World Health Organization and the Thai Ministry of Public Health, 26-27 April 2004, Bangkok, Thailand. Vaccine 2005, 23:2869-95.

12. Petersen LR, and Roehrig JT. West Nile virus: a reemerging global pathogen. Emerg Infect Dis 2001, 7:6114.

13. Public Health Agency of Canada. West Nile virus What the Government of Canada is Doing. Available online at: http://www.phac-aspc.gc.ca/wn-no/role_e.html (Accessed November 1, 2007).

14. Ontario Ministry of Health and Long Term Care. West Nile virus 2006: Bird Surveillance. Available online at http://www.health.gov.on.ca/english/providers/program/pubh 
ealth/ westnile/wnv 06/wnv birds.html (Accessed November 1, 2007).

15. Komar N, Langevin S, Hinten S, Nemeth N, Edwards E, Hettler D, Davis B, Bowen R, Bunning M. Experimental infection of North American birds with the New York 1999 strain of West Nile virus. Emerg Infect Dis 2003, 9:311-322. 16. Rappole JH, Derrickson SR, Hubalek Z. Migratory birds and spread of West Nile virus in the Western Hemisphere. Emerg Infect Dis 2000, 6:319-328.

17. Johnson GD, Eidson M, Schmit K, Ellis A, Kuldorff M. Geographic prediction of human onset of West Nile virus using dead crow clusters: An evaluation of year 2002 data in New York State. Amer J Epid 2005, 163:171-180.

18. Eidson M, Kramer L, Stone W, Hagiwara Y, Schmit K, New York State West Nile Virus Avian Surveillance Team. Dead bird surveillance as an early warning system for West Nile virus. Emerg Infect Dis 2001, 7:631-635.

19. Beroll H, Berke O, Wilson J, Barker IK. Investigating the spatial risk distribution of West Nile virus disease in birds and humans in southern Ontario from 2002 to 2005. Population Health Metrics 2007, 5:3.

20. Canadian Cooperative Wildlife Health Centre. Public Health Agency of Canada. West Nile virus - What the Government of Canada is doing. Available online at: http://www.cnphi-wnv.ca/healthnet/Dataquery.do (Accessed September 10, 2007).

21. Ontario Ministry of Health and Long Term Care. West Nile virus 2006: Human Surveillance. Available online at: http://www.health.gov.on.ca/english/providers/program/ pubhealth/westnile/wnv_06/wnv_humans.html (Accessed September 10, 2007).

22. Statistics Canada. Estimates of population, by age group and sex, Canada, provinces, territories, health regions (June 2005 boundaries) and peer groups. Available online at: http://cansim2.statcan.ca/cgiwin/cnsmcgi.exe?Lang=E\&RootDir $=\mathrm{CII} / \&$ ResultTemplate $=$ CII/CII_\&Array_Pick=1\&ArrayId=1095315 (Accessed September 19, 2007).
23. Statistics Canada. Health Region Boundary Files. Available online at http://www.statcan.ca/english/freepub/82-402-

XIE/2005001/region.htm (Accessed November 1, 2007).

24. Ontario Ministry of Health and Long-term care - Public Health Division. West Nile virus Preparedness and Prevention Plan 2006. Available online at http://www.health.gov.on.ca/

english/public/pub/ministry_reports/wnv_plan_2006/wnv_pl an_2006_full.pdf (Accessed November 1, 2007).

25. Public Health Agency of Canada. National Notifiable Diseases. Available online at http://dsol-smed.phacaspc.gc.ca/dsol-smed/ndis/list_e.html (Accessed November $1,2007)$.

26. Kulldorff M, A spatial scan statistic. Commun in Stat 1997, 26:1481-1496.

27. Kulldorff M, Information Management Services, Inc: SaTScan $^{\text {TM }}$ v6.0: Software for the spatial and space-time scan statistics. 2006 [http://www.satscan.org/].

28. Berke O. Exploratory spatial relative risk mapping. Prev Vet Med 2005, 71:173-182.

29. Berke O. Exploratory disease mapping: kriging the spatial risk function from regional count data. Int $J$ Health Geogr 2004, 3:18.

30. R Development Core Team: R: A language and environment for statistical computing. $R$ Foundation for Statistical Computing, Vienna, Austria 2005 [http://www.Rproject.org]. ISBN 3-900051-07-0

31. ArcMap 9.1. Environmental System Research Institute, ESRI Inc. 380 New York St., Redlands, CA92373, http://www.esri.com.

32. Tango T, Takahashi K. A flexibly shaped spatial scan statistic for detecting clusters. Int J Health Geogr 2005, 4:11. 33. Rainham DGC. Ecological Complexity and West Nile Virus: Perspectives on Improving Public Health Response. Canadian Journal of Public Health 2005, 96:37-40. 